\title{
Knowledge of young African American adults about heart disease: a cross-sectional survey
}

Donna M Winham ${ }^{1 *}$ and Kathleen $\mathrm{M}$ Jones $^{2}$

\begin{abstract}
Background: African Americans have higher rates of cardiovascular disease (CVD) mortality than other ethnic groups. Young adults are prime targets for intervention strategies to prevent and reduce disease risk. The study purpose was to determine the level of knowledge of lifestyle risk factors for CVD among young African American adults in Phoenix. The results will be used to guide the development of CVD outreach programs targeted to this population. The Health Belief Model was used as a conceptual framework.

Methods: A convenience sample of 172 African American men and women aged 18-26 years completed a questionnaire adapted from the American Heart Association national surveys. Descriptive statistics were compared by age, gender, education level, and health status variables including BMI, smoking status, and physical activity.

Results: Some aspects of heart-disease were well known among young adult African Americans. Knowledge of certain other important risk factors (menopause) and preventive behaviors (eating fewer animal products), however, was more variable and inconsistent among the respondents. Differences in knowledge of individual variables was greater by education level than by gender overall. Predictors of a summary CVD knowledge score included higher education, female gender, and high self-efficacy (adjusted $R^{2}=0.158, p<.001$ ). Predictors of self-efficacy in changing CVD risk were higher education and perceived low risk of CVD (adjusted $R^{2}=0.064, p<.001$ ), but these characteristics explained only $6 \%$ of the variance.

Conclusions: Evaluation of baseline knowledge of CVD is essential before designing and implementing health promotion programs. Existing strengths and weaknesses in knowledge can guide tailoring of programs to be more effective. Further research would help to identify the range of other characteristics that determine knowledge and risk perception.
\end{abstract}

\section{Background}

Heart disease is the leading cause of death in the United States, claiming approximately 700,000 lives-nearly $30 \%$ of all United States (US) deaths-each year [1]. African Americans constitute $12.8 \%$ of the US population, yet their risk of developing cardiovascular disease (CVD) is three times greater than Whites and they also have twice the risk of mortality $[2,3]$. To complicate matters further, African Americans have higher premature CVD deaths than Whites and may have earlier onset of disease $[4,5]$.

Differences in access to and quality of health care, dietary intakes, lifestyle factors (e.g., smoking),

\footnotetext{
* Correspondence: donna.winham@asu.edu

'Nutrition Program, College of Nursing and Health Innovation, Arizona State University, Mesa, Arizona, USA

Full list of author information is available at the end of the article
}

neighborhood characteristics, socioeconomic status, sociocultural attitudes toward disease, persistent racial discrimination, and genetics have been offered as explanations for poor CVD health outcomes among African Americans [6,7]. Yet not all of these factors contribute to CVD risk for every African American. Many disease risk factors are amenable to change, and all individuals can reduce their risk of CVD morbidity and mortality, especially if healthful behaviors are established in childhood or changed in young adulthood.

Knowledge of CVD risk factors is essential for a person to make an informed decision about engaging in or continuing certain behaviors that may increase disease risk, such as smoking, not exercising, or consuming high-fat foods [8]. The Health Belief Model (HBM) suggests that a person must feel susceptible to the disease in order to change his or her behaviors $[9,10]$. Thus,

\section{() Biomed Central}


there must be perceived risk or some willingness to change for many individuals to alter behaviors. For behavior change to occur, an individual must be aware of the potential negative consequences of his or her current actions. In this sense, knowledge alone may be insufficient to cause behavior change, and without a perception of self-risk, there is little impetus to change [10,11].

The successful development and implementation of a health promotion program, depends upon identification of the scope and breadth of baseline knowledge among the targeted group members [12]. For example, regional differences in beliefs and knowledge may exist. If programs are to be culturally appropriate and salient for the target audience, baseline information is essential before investing in new program development or adapting existing programs in a given region [13].

Most researchers have used national surveys [14] or surveys undertaken in the rural South $[7,15]$ to study CVD risk knowledge among African Americans. National surveys assume ethnic group homogeneity and can miss local details such as the specific and unique characteristics of a certain population. African Americans are a heterogeneous group in terms of income, education, cultural affiliation, religiosity, and life experiences [16]. Although more than 50\% of African Americans live in the southern US, one cannot assume these individuals' characteristics are representative of African Americans living in other regions where the political, economic, and social environments are different [17]. In fact, CVD mortality is higher in the southeastern states for people of all races and ethnicities [18]. The African American experience in Arizona may be different because of the history of political and social organizations in the region and the distance, both in time and geography, from the lifestyle behaviors of the rural South [19]. Knowledge about CVD may differ as well. Nevertheless, despite recommendations that providers determine baseline knowledge before applying evidencebased guidelines on health promotion with communities in other settings and locations, intervention programs are not always tailored to fit the community of interest [20]. This can result in poor intervention outcomes and wasted efforts.

CVD prevention and intervention research often focuses on middle-aged adults with the signs and symptoms of disease. These individuals may have greater selfefficacy and motivation to modify behavior that reduces CVD risk than their adult peers who do not have CVD $[21,22]$. Moreover, health-promotion and prevention efforts, if started early enough, can have a greater impact on quality of life than therapeutic interventions alone when enacted at a more advanced age [23].
For young adults, behavior patterns and trajectories established now will influence their health for a lifetime [24]. Young adults are at a critical transition period in their lives. They establish adulthood health behaviors, move from their parents' home to live independently, and, for some, begin having children during this life stage [24]. Behavior patterns or decisions about lifestyle choices (e.g., dietary intakes, physical activity, and smoking) made in early adulthood initiate health trajectories that predict chronic-disease risk, including CVD, later in life [25-27]. Furthermore, individuals who become parents may sway the health behaviors of the next generation by the examples they set in diet and lifestyle behaviors. The intergenerational effects are amplified because many young adults are involved with the care of their parents or grandparents as well as their own children. Thus, young adults may be strategically poised to influence health behaviors throughout all stages of the life cycle [28].

Tailoring health messages ensures that the target group receives information that is salient to their concerns and situation. If people hear the same message they already know (e.g., high cholesterol is bad), but they do not know how to act on this information or perceive it as irrelevant, they may dismiss the message [17]. Process evaluation or crosschecking to determine if messages are understood correctly and appropriate actions are taken is important after program initiation as well.

African Americans are 4.3\% of Arizona's total population, yet their CVD mortality rate is higher in the state than it is among other ethnic/racial groups [29,30]. In 2007, African Americans living in Arizona had a 60\% greater risk of dying from CVD than Arizona's Asian population, which had the lowest risk of death due to heart disease [29]. As a small and geographically spreadout minority, targeted outreach efforts to improve health and reduce CVD risk for African Americans are needed [17].

The HBM, which focuses on an individual's perceptions about a disease state or condition, guided the study design and research question development. The HBM states that for behavior change to occur individuals must perceive a disease or condition as serious (perceived seriousness), consider themselves vulnerable to developing the disease (perceived susceptibility), see positive outcomes associated with the desired behavior change (perceived benefits) and no obstacles to changing behavior (perceived barriers). Knowledge about a disease and risk as well as confidence in one's ability to take all the steps associated with behavior change (perceived self-efficacy), added to the model as it was developed, is also now an integral part of the HBM. These key 
concepts are collectively referred to as attitudes in the current study [9].

The research objectives were to (1) describe knowledge, attitudes, and practices about CVD among young adult African Americans in metropolitan Phoenix and (2) determine if perceived seriousness, perceived susceptibility, perceived self-efficacy and perceived benefits related to CVD risk varied by gender, age, education, and health status.

\section{Methods}

\section{Study design and population}

The design was a cross-sectional descriptive study. A convenience sample of young adult men and women who self-identified as having African ancestry was recruited. For the purpose of the study, a young adult was defined as a person between the ages of 18 and 29 years [31]. Targeted recruitment efforts were made to include participants from all socioeconomic and educational backgrounds, including those who were in the Special Supplemental Nutrition Program for Women, Infants, and Children (WIC), African American churches, campus groups, and local community organizations. Data were collected between May and December 2007. During preliminary analysis participants aged 27-29 ( $\mathrm{n}=24)$ were excluded from further analysis because almost all of them were college educated (22/ $24)$. Any observed associations with the outcome measures and age would be driven by education alone. Therefore, retention of these older participants would have confounded observed associations because there were only 2 participants in this age group with less education. The final sample size consisted of 172 participants aged 18-26 years.

\section{Survey instruments and data collection procedures}

A demographic questionnaire was developed that included questions about age and education. With permission from the American Heart Association (AHA) a national survey on women's knowledge, attitudes, and practices with regard to heart disease was used [14]. The questionnaire has been used in four national telephone surveys with women conducted by the AHA in 1997, 2000, 2003, and 2006 [14,32]. The survey asks about specific heart-disease domains such as health behavior awareness, knowledge of CVD risk factors, knowledge of symptoms and outcomes, treatment options, awareness of self-risk and preventive behaviors.

Several questions from the AHA questionnaire comprised the HBM conceptual framework. Perceived susceptibility was estimated using the statement "I am at low risk for a heart attack or stroke for a person my age" from the AHA questionnaire [14,32]. Self-efficacy was evaluated with the statement "There is nothing I can do to help prevent myself from getting heart disease." Both statements had four response categories, ranging from agree strongly to disagree strongly. Perceived seriousness of heart disease was assessed by two questions on the leading cause of death and on the outcomes of CVD. Perceived benefits were based on knowledge of disease outcomes and preventive behaviors. Cues to action were addressed through the number of risk factors and symptoms each person had (BMI, cholesterol, smoking, physical activity). Although part of the HBM, perceived barriers were not directly examined in this descriptive study because our focus was on baseline knowledge, not change.

The original AHA questionnaire targeted women aged 25 years or older. Consequently slight wording changes were made to address both male and female respondents and to convert the questionnaire to be self-administered rather than be delivered by an interview. Several questions about the use of hormone replacement therapy and chronic disease diagnosis were omitted because these topics were deemed less applicable to young adults. Initial pilot testing for content validity after these minor modifications was done with a convenience sample of nine African American men and women aged 21-32. For pilot testing, African American ethnicity was more important than the exact age of the convenience sample. Minor formatting changes were made before official data collection.

Most participants contacted the researchers in response to email or listserv advertisements of the study (117/172). After the initial contact with a participant by email or telephone, the researcher arranged to meet at a mutually convenient time and public location to complete the survey (e.g., local library or community center). Three did not show up for scheduled appointments, and one declined to complete the survey. The other 55 participants were convenience samples from three churches and two WIC clinics. At these sites, the researcher set up with a table and participants approached her for more information. We were unable to track the number of people who declined to participate because these were convenience samples at these sites. Participants received a \$15 gift card to a major retailer after they completed the survey. Participants provided written, informed consent, and all procedures were approved by the Arizona State University Research Compliance Office Institutional Review Board.

\section{Data management and transformations}

Data entry and cleaning were ongoing over the course of the study. The continuous variables of age and education were correlated. To reduce confounding effects, two dichotomous variables were created based on logical breaks in the sample distributions. Age was 
dichotomized at the approximate $50^{\text {th }}$ cumulative percentile into two similarly sized groups of those aged 1822 years and those aged 23-26 years. The bivariate education variable was split between those without a college education and those with any completed years of college.

A composite measure of health status risk was created by summing the presence or absence of risk behaviors. Points were assigned as follows: 1 point for current smoking, 1 point for body mass index (BMI) in overweight or obesity range, 1 point for not exercising four or more times per month. For analysis, these scores were categorized into tertiles of 0 risk factors, 1 risk factor, and $2+$ risk factors.

Three summary knowledge index variables were created to use in multiple regression analysis to test the research hypotheses. The scores for the 12-item truefalse questions on understanding of heart disease, the 6item question of knowledge concerning heart attack warning signs, and the 5-item question of knowledge concerning stroke warning signs were coded to reflect 1 point for each correct answer and 0 points for incorrect answers. Each section was summed individually to create three separate indices: knowledge of heart-disease, of the warning signs of heart attack, and of the warning signs of stroke $[10,33]$.

\section{Statistical analysis and modeling}

Univariate relationships of continuous variables were analyzed between age and gender groups by independent t-tests. Chi-square was used to compare questionnaire variables by gender and education. Statistical significance was determined by $p<0.05$. P-values below 0.05 are shown, but owing to multiple comparison we recommend that $\mathrm{p}$-values $<0.05$ but $>0.01$ should be regarded as trend values. Three multivariate linear regression models were tested to evaluate predictors of heart-disease knowledge, perceived susceptibility, and perceived self-efficacy. No adjustments were made for multiple comparisons and statistical tests.

\section{Results}

\section{Demographics}

A total of 172 adults aged 18-26 years old who selfidentified as African American, Black or of African ancestry completed the study. Of the 172 participants, $36 \%$ were men, and $64 \%$ were women. Seventy-one percent $(71 \%)$ had some college education or vocational training. Those with a college education were one year older on average than those without any college education. Statistically significant differences between genders were noted for education level, with fewer men than women having completed some college. Within education categories, those without college education had more children in the household. Table 1 shows the demographic characteristics for the sample classified by gender and college education.

\section{Self-reported risk factors and preventive behaviors}

Based on self-reported heights and weights, calculated BMI values indicated that $29.2 \%$ of the sample participants were overweight (i.e., BMI $=25.0$ - 29.9) and $25.7 \%$ were obese (BMI $\geq 30.0$; Table 2 ). The majority of participants had never smoked cigarettes. Current smoking was significantly lower among college-educated participants, than among those without any college education, but smoking did not differ by gender. More men than women reported exercising four or more times per week, Women were more likely than men to have had a cholesterol screen in the past 18 months). Respondents with college education were more likely than those without any college education to report their physicians had discussed heart disease with them. Almost $40 \%$ of the sample had two or more CVD risk factors (Table 2).

\section{Perceived seriousness of heart disease}

When asked as an open-ended question, "What is the leading cause of death?," $27 \%$ of the respondents stated obesity, followed by heart disease (16\%), poor diet/ unhealthy lifestyle (16\%), HIV/AIDS (13\%), cancer $(11 \%)$, diabetes $(6 \%)$, and other causes $(11 \%)$. When given a list of options as a closed-ended question for the leading cause of death, heart disease was then reported most often (34\%), followed by cancer (21\%) and HIV/ AIDS (12\%). Awareness of heart disease as the leading cause of death was significantly higher among college educated $(p=0.003)$ and older respondents $(p=0.012)$. Most participants felt they were moderately well informed about heart disease among African Americans (51\%). Slightly less (47\%) felt they were well informed about stroke among African Americans. At the same time, 24\% stated they were not at all informed about heart disease, and 33\% said the same for stroke.

\section{Perceived susceptibility and risk}

Almost $17 \%$ of the respondents strongly agreed with the statement "I am at low risk for a heart attack or stroke for a person my age." Another $43.6 \%$ agreed somewhat with the statement, but $39.5 \%$ either disagreed somewhat or disagreed strongly indicating they felt they were at risk. Other prevention and knowledge beliefs about heart disease are shown in Table 3. To determine their degree of perceived disease risk, participants were asked about their concerns of other diseases or risks, including heart disease as part of the AHA questionnaire [14]. Participants were asked how much they worried (a lot, a little, do not worry at all) about 12 diseases or risk factors: heart disease/heart attack, AIDS, diabetes, general 
Table 1 Demographic characteristics of young adult African American participants $(\mathbf{N}=172)$

\begin{tabular}{|c|c|c|c|c|c|}
\hline Characteristics & Total & $\begin{array}{r}\text { Male } \\
(n=62) \\
\end{array}$ & $\begin{array}{r}\text { Female } \\
(n=110)\end{array}$ & $\begin{array}{r}\text { College } \\
(n=116)\end{array}$ & $\begin{array}{r}\text { No college } \\
(n=56)\end{array}$ \\
\hline \multicolumn{6}{|l|}{ Age in years } \\
\hline $18-21$ & 55.2 & 66.1 & 49.1 & 48.3 & 69.6 \\
\hline $22-26$ & 44.8 & 33.9 & 50.9 & 51.7 & 30.4 \\
\hline \multicolumn{6}{|l|}{ Years of Education } \\
\hline College & 71.4 & 56.5 & 73.6 & - & - \\
\hline No college & 28.6 & $43.5^{1}$ & $26.4^{1}$ & & \\
\hline \multicolumn{6}{|l|}{ Marital Status (\%) } \\
\hline Single/Divorced & 86.0 & 83.7 & 84.5 & 85.2 & 89.3 \\
\hline Married/Live w/partner & 15.5 & 11.3 & 15.5 & 14.8 & 10.7 \\
\hline \multicolumn{6}{|c|}{ Children under 18 years in household (\%) } \\
\hline Has $1+$ child & 23.8 & $6.5^{2}$ & $33.6^{2}$ & $16.5^{3}$ & $37.5^{3}$ \\
\hline No children & 76.2 & 93.5 & 66.4 & 83.5 & 62.5 \\
\hline \multicolumn{6}{|l|}{ Household Income (\%) } \\
\hline Under $\$ 10,000 / y$ & 25.2 & 24.5 & 25.5 & 23.6 & 29.2 \\
\hline $10-19,999$ & 14.8 & 7.5 & 18.6 & 14.2 & 16.7 \\
\hline $20-29,999$ & 16.8 & 18.9 & 15.7 & 15.1 & 18.8 \\
\hline $30-39,999$ & 16.1 & 18.9 & 14.7 & 17.9 & 12.5 \\
\hline 40-49,999 & 7.1 & 7.5 & 6.9 & 9.4 & 2.1 \\
\hline $50-74,999$ & 12.9 & 13.2 & 12.7 & 12.3 & 14.6 \\
\hline 75- or more/y & 7.1 & 3.8 & 2.9 & 2.8 & 4.2 \\
\hline
\end{tabular}

All values are percentages. ${ }^{1} p=0.021 ;{ }^{2} p=0.000 ;{ }^{3} p=0.003$.

cancer, breast cancer, stroke, lung cancer, Alzheimer's, osteoporosis, smoking, drug addiction/alcoholism, and violent crime.

Over $50 \%$ of the participants expressed that they "did not worry at all" about 7 of these 12 conditions (AIDS, stroke, lung cancer, Alzheimer's, osteoporosis, smoking, drug addiction/alcoholism). Less than $10 \%$ worried "a lot" about these conditions with the exception of $17.3 \%$ who worried a lot about AIDS. More people worried "a lot" about the remaining five conditions or risks, with over a quarter of respondents naming diabetes as of the greatest concern. In order, the other 4 were, cancer in general, breast cancer, violent crime, and heart disease/ heart attack. Women expressed significantly greater concern than men about developing cancer in general $(25.8 \%$ vs. $8.1 \%)$ and breast cancer $(27.6 \%$ vs. $2.7 \%)$. No other significant differences were seen by gender or education.

\section{Knowledge of risk factors for heart disease}

Knowledge of risk factors for heart disease and strategies for prevention are shown in Table 4. Recognition of some risk factors was very high. For example, most participants knew that being overweight (91.9\%), having a family history of heart disease $(88 \%)$, and having high blood pressure (84\%) were causes of heart disease. Men in general had higher awareness of many risk factors, including low estrogen ( $24 \%$ vs. $21 \%)$ and menopause
(18\% vs. $15 \%)$ than women. As Table 4 shows, collegeeducated participants had a significantly higher knowledge of risk factors than their peers who were not college educated.

Knowledge of ways to prevent or reduce the risk of heart disease was relatively high among all respondents for exercising (94\%), losing weight (87\%), reducing stress (86\%), and quitting smoking (85\%). Although $77 \%$ of all respondents knew that reducing dietary cholesterol lowered heart-disease risk, only $37 \%$ reported that reducing animal products in the diet did the same. A higher percentage of those with a college education than of those without a college education knew of the risk factors (Table 3).

\section{Knowledge of the symptoms and outcomes of heart disease}

A series of 12 true-false statements from the AHA questionnaire determined understanding of heart disease and some behaviors associated with prevention (Table 5) [14]. Several significant differences were observed by gender and education. More women than men knew that heart disease was the leading cause of death among women, that women had atypical symptoms of heart attack, that men and postmenopausal women were equally likely to have heart attacks, and that men were no more likely than women to die from heart disease. Compared with respondents who had a college 
Table 2 Health behavior and risk factor characteristics of young adult African American participants $(\mathbf{N}=172)$

\begin{tabular}{|c|c|c|c|c|c|}
\hline Characteristics & Total & $\begin{array}{r}\text { Male } \\
(n=62)\end{array}$ & $\begin{array}{r}\text { Female } \\
(n=110)\end{array}$ & $\begin{array}{r}\text { College } \\
(n=116)\end{array}$ & $\begin{array}{r}\text { No college } \\
(n=56)\end{array}$ \\
\hline \multicolumn{6}{|l|}{ BMI category (\%) } \\
\hline Underweight & 1.8 & 0 & 2.8 & 2.6 & 0 \\
\hline Normal & 43.3 & 40.3 & 45.0 & 41.4 & 47.3 \\
\hline Overweight & 29.2 & 35.5 & 25.7 & 26.9 & 34.5 \\
\hline Obese & 25.7 & 24.2 & 26.6 & 29.3 & 18.2 \\
\hline \multicolumn{6}{|l|}{ Exercise frequency (\%) } \\
\hline Almost never & 16.3 & 9.7 & 20.0 & 18.1 & 12.5 \\
\hline Twice a month & 14.0 & 6.5 & 18.2 & 16.4 & 8.9 \\
\hline Once a week & 18.6 & 14.5 & 20.9 & 17.2 & 21.4 \\
\hline 2-3 times per week & 22.1 & 21.0 & 22.7 & 23.3 & 19.6 \\
\hline 4+ times per week & 29.1 & $48.4^{1}$ & $18.2^{1}$ & 25.0 & 37.5 \\
\hline \multicolumn{6}{|l|}{ Smoking frequency (\%) } \\
\hline Never smoked & 70.9 & 69.4 & 71.8 & $76.7^{2}$ & $58.9^{2}$ \\
\hline Used to smoke, but quit & 12.8 & 14.5 & 11.8 & 12.9 & 12.5 \\
\hline Smoke, but not every day & 8.7 & 9.7 & 8.2 & 6.9 & 12.5 \\
\hline Smoke $1+$ cigarettes/day & 7.6 & 6.5 & 8.2 & 3.4 & 16.1 \\
\hline \multicolumn{6}{|l|}{ Risk factor summary score (\%) } \\
\hline No risk factors & 20.9 & 22.6 & 20.0 & 22.4 & 17.9 \\
\hline One risk factor & 44.2 & 53.2 & 39.1 & 41.4 & 50.0 \\
\hline Two+ risk factors & 39.9 & 24.2 & 40.9 & 36.2 & 32.1 \\
\hline \multicolumn{6}{|c|}{ Cholesterol check in last 18 months (\%) } \\
\hline Yes & 25.6 & $16.1^{3}$ & $30.9^{3}$ & 27.6 & 21.4 \\
\hline \multicolumn{6}{|c|}{ Blood pressure check past 18 months (\%) } \\
\hline Yes & 83.7 & 82.3 & 84.5 & 83.6 & 83.9 \\
\hline \multicolumn{6}{|c|}{ Doctor discussed heart disease with you (\%) } \\
\hline Yes & 20.9 & 14.5 & 24.5 & $25.9^{4}$ & $10.7^{4}$ \\
\hline
\end{tabular}
${ }^{4} p=0.022$.

education, fewer respondents who did not have a college education knew that Black and Hispanic women were more likely than White women to have a heart attack or stroke. Those without a college education also were less aware than those with a college education that there were treatment options to break up blood clots. Women and those respondents with a college education had significantly higher summary index values than men or those who did not have a college education.

Participants' ability to recognize the warning signs for heart attack and stroke was assessed with 11 questions. The percentage of correct responses for the warning signs of a heart attack were high for chest pain (97\%) and tightness in the chest (94\%) but low for nausea $(30 \%)$ and fatigue $(50 \%)$. Pain spreading to the shoulder, neck, or arms was recognized by $72 \%$ of the group overall. For warning signs of stroke, recognition of weakness on one side $(85 \%)$ and inability to talk or understand speech $(80 \%)$ were relatively high, but a sudden, severe headache (53\%) was less well known. There were no significant differences in knowledge by gender or education. A summary index score was created based on the number of correct answers.

\section{Self-efficacy to change heart-disease risk}

Self-efficacy was evaluated with the statement "There is nothing I can do to help prevent myself from getting heart disease." The majority of respondents (73.1\%) strongly disagreed with this statement. Slightly over $11 \%$ disagreed somewhat and only $15.8 \%$ agreed somewhat or agreed strongly (Table 3).

\section{Multivariate analysis}

Three multivariate linear regression models were developed to determine (a) if differences in CVD knowledge score were predicted by sociodemographic characteristics (gender, age, education) and health status as estimated by number of risk factors (smoking, lack of exercise, overweight/obesity), (b) if perceived susceptibility of CVD risk was associated with gender, age, education, and health status, and (c) if perceived self-efficacy was associated with these same variables. Predictors of 
Table 3 Prevention and knowledge beliefs about heart disease by percent of respondents and education level $(N=171)$

\begin{tabular}{|c|c|c|c|c|c|}
\hline HD Statement & $\begin{array}{r}\text { Agree } \\
\text { Strongly }\end{array}$ & $\begin{array}{r}\text { Agree } \\
\text { Somewhat }\end{array}$ & $\begin{array}{r}\text { Disagree } \\
\text { Somewhat }\end{array}$ & $\begin{array}{l}\text { Disagree } \\
\text { Strongly }\end{array}$ & \\
\hline \multirow{3}{*}{$\begin{array}{l}\text { When I think of heart disease, I most often think of someone having a heart } \\
\text { attack and dying quickly }\end{array}$} & 9.9 & 44.4 & 31.0 & 14.6 & Total \\
\hline & 7.8 & 38.8 & 35.3 & 18.1 & College \\
\hline & 14.5 & 56.4 & 21.8 & 7.3 & No coll. \\
\hline \multirow{3}{*}{$\begin{array}{l}\text { When I think of stroke, I most often think about someone having a long-term } \\
\text { disease that will reduce the quality of their life. }\end{array}$} & 18.7 & 42.7 & 22.2 & 16.4 & Total \\
\hline & 19.0 & 50.9 & 24.1 & 18.1 & College \\
\hline & 18.2 & 42.7 & 18.2 & 12.7 & No coll. \\
\hline \multirow{3}{*}{$\begin{array}{l}\text { By taking estrogen replacement therapy, I (or women if a male) can help reduce } \\
\text { my risk for heart disease. }\end{array}$} & 2.9 & 47.4 & 38.6 & 11.1 & Total \\
\hline & 4.3 & 50.0 & 34.5 & 11.2 & College \\
\hline & 0 & 41.8 & 47.3 & 10.9 & No coll. \\
\hline \multirow{3}{*}{$\begin{array}{l}\text { I am comfortable talking with my doctor about preventative and treatment } \\
\text { options regarding my health. }{ }^{2}\end{array}$} & 66.7 & 20.5 & 5.8 & 7.0 & Total \\
\hline & 74.1 & 18.1 & 2.6 & 5.2 & College \\
\hline & 50.9 & 25.5 & 12.7 & 10.9 & No coll. \\
\hline \multirow{3}{*}{$\begin{array}{l}\text { It is easy to find accurate and easy to understand information about heart disease } \\
\text { and stroke. }\end{array}$} & 34.3 & 50.0 & 13.4 & 2.3 & Total \\
\hline & 40.5 & 45.7 & 12.1 & 1.7 & College \\
\hline & 21.4 & 58.9 & 16.1 & 3.6 & No coll. \\
\hline \multirow{3}{*}{$\begin{array}{l}\text { There is nothing I can do to help prevent myself from getting heart disease. } \\
(H B M \text { Self-efficacy) }\end{array}$} & 7.0 & 8.8 & 11.1 & 73.1 & Total \\
\hline & 5.2 & 5.2 & 6.0 & 83.6 & College \\
\hline & 10.9 & 16.4 & 21.8 & 50.9 & No coll. \\
\hline \multirow{3}{*}{$\begin{array}{l}\text { I am at low risk for heart attack or stroke for a person my age. (HBM Perceived } \\
\text { Risk) }\end{array}$} & 16.9 & 43.6 & 27.9 & 11.6 & Total \\
\hline & 18.1 & 44.0 & 28.4 & 9.5 & College \\
\hline & 14.3 & 42.9 & 26.8 & 16.1 & No coll. \\
\hline
\end{tabular}

Note. Data are \% reporting; ${ }^{1} p=0.023 ;{ }^{2} p=0.006 ;{ }^{3} p=0.000$

the CVD knowledge score included higher education, female gender, high self-efficacy $\left(F=11.66\right.$, adjusted $R^{2}$ $=0.158, p<.001)$. Higher education and perceived low risk of CVD predicted perceived self-efficacy to heart disease $\left(\mathrm{F}=6.81\right.$, adjusted $\left.\mathrm{R}^{2}=0.064, p<.001\right)$. Male gender, and low self-efficacy were predictors of perceived susceptibility to CVD $\left(\mathrm{F}=4.08\right.$, adjusted $\mathrm{R}^{2}=$ $0.035, p<.019)($ Table 6).

\section{Discussion}

Our findings demonstrate that some aspects of heartdisease are well known among young adult African Americans. Knowledge of certain other important risk factors and preventive behaviors, however, was more variable and inconsistent among the respondents. There was wide-recognition of the link between being overweight and heart disease. Perhaps more relevant messages and targeted education focused on an area of incongruity in knowledge would resonate better with young adults. One striking observation was that $76.6 \%$ of the participants knew that high cholesterol was a major cause of heart disease, but only $37.4 \%$ recognized that reducing animal products in the diet is a preventive behavior (Table 4). There appears to be a lack of understanding that high blood cholesterol is associated with consumption of animal products that contain saturated fats. An outreach campaign that focuses on clarification of diet/lifestyle factors that elevate blood cholesterol, including consumption of saturated fat found in animal products would help correct this misperception. These specific differences in awareness need to be considered in the formative evaluation stage of developing health promotion and program planning efforts to a target population [9].

Other researchers have found that knowledge about heart disease differ by gender and education level [34]. Our study supports differences in knowledge by gender, but not always in favor of young adult women. One unexpected finding was that more men than women reported awareness of the effects of low estrogen, menopause, and hormone replacement therapy on heart disease. Women were, however, significantly more 
Table 4 Percentage of respondents who correctly identified risk factors and prevention strategies $(N=172)$

\begin{tabular}{|c|c|c|c|c|c|}
\hline \multicolumn{6}{|c|}{ "Based on what you know, what are the major causes of heart disease?" } \\
\hline Heart Disease (HD) Risk Factors & Total & $\begin{array}{l}\text { Male } \\
(n=62)\end{array}$ & $\begin{array}{l}\text { Female } \\
(n=110)\end{array}$ & $\begin{array}{l}\text { College } \\
(n=116)\end{array}$ & $\begin{array}{l}\text { No college } \\
(\mathrm{n}=56)\end{array}$ \\
\hline Being overweight & 91.9 & 91.9 & 91.8 & 94.0 & 87.5 \\
\hline Family history of $\mathrm{HD}$ & 87.8 & 88.7 & 87.3 & 90.5 & 82.1 \\
\hline High blood pressure & 83.7 & 82.3 & 84.5 & $91.4^{1}$ & $67.9^{1}$ \\
\hline Stress & 77.3 & 80.6 & 75.5 & $83.6^{2}$ & $64.3^{2}$ \\
\hline High cholesterol & 76.7 & 79.0 & 75.5 & 81.0 & 67.9 \\
\hline Diabetes & 68.6 & 72.6 & 66.4 & 69.8 & 66.1 \\
\hline Not exercising & 66.3 & 69.4 & 64.5 & $75.9^{3}$ & $46.4^{3}$ \\
\hline Smoking & 62.8 & 67.7 & 60.0 & 62.9 & 62.5 \\
\hline Racial/ethnic heritage & 57.6 & 61.3 & 55.5 & $64.7^{4}$ & $42.9^{4}$ \\
\hline Drinking alcohol & 51.2 & 56.5 & 48.2 & 50.0 & 53.6 \\
\hline Aging & 39.5 & 45.2 & 36.4 & 43.1 & 32.1 \\
\hline Stroke & 33.1 & 24.2 & 38.2 & 31.9 & 35.7 \\
\hline High triglycerides & 25.0 & 29.0 & 22.7 & $30.2^{5}$ & $14.3^{5}$ \\
\hline Low levels of estrogen & 22.1 & 24.2 & 20.9 & 26.7 & 12.5 \\
\hline Menopause & 15.7 & 17.7 & 14.5 & $19.8^{6}$ & $7.1^{6}$ \\
\hline \multicolumn{6}{|c|}{ "Which of the following do you believe can prevent or reduce the risk of getting heart disease?" } \\
\hline \multirow[t]{2}{*}{ Heart Disease (HD) Risk Factors } & Total & Male & Female & College & No college \\
\hline & & $(n=62)$ & $(n=110)$ & $(n=116)$ & $(n=56)$ \\
\hline Getting physical exercise & 93.6 & 93.4 & 93.3 & 94.8 & 90.9 \\
\hline Losing weight & 86.5 & 90.2 & 87.5 & 88.8 & 81.8 \\
\hline Reducing stress & 86.0 & 86.9 & 87.5 & 88.8 & 80.0 \\
\hline Quitting smoking & 84.8 & 90.2 & 84.6 & 81.9 & 90.9 \\
\hline Reducing sodium or salt in diet & 81.9 & 85.2 & 86.5 & 86.2 & 72.7 \\
\hline Reducing dietary cholesterol & 76.6 & 82.0 & 76.0 & 81.0 & 67.3 \\
\hline Taking vitamins $\mathrm{E}, \mathrm{C}$, or $\mathrm{A}$ & 60.2 & 70.5 & 52.9 & 60.3 & 60.0 \\
\hline Taking vitamins w/folic acid & 43.9 & 50.8 & 40.4 & 49.1 & 32.7 \\
\hline Reducing animal products in diet & 37.4 & 45.9 & 40.4 & 42.2 & 27.3 \\
\hline Hormone replacement therapy & 18.1 & 24.6 & 14.4 & 17.2 & 20.0 \\
\hline Aromatherapy & 14.0 & 16.4 & 11.5 & 15.5 & 10.9 \\
\hline
\end{tabular}

Note. Data are percentage of respondents answering correctly. ${ }^{1} p=0.000 ;{ }^{2} p=0.006 ;{ }^{3} p=0.000 ;{ }^{4} p=0.008 ;{ }^{5} p=0.025 ;{ }^{6} p=0.043$.

knowledgeable than men about women having atypical heart-disease symptoms, increased risk of dying from heart disease, and heart disease as a leading cause of death among this gender group.

Differences in knowledge by education level were more pronounced than those by gender. Although this finding was anticipated, it highlights the importance of tailoring health promotion efforts to specific segments of the targeted population by education level, rather than by ethnicity or gender alone. In some cases, the knowledge gap about a risk factor by education status was quite large. For example, while $91.4 \%$ of the respondents who had a college education knew that high blood pressure was a risk factor for heart disease, only $67.9 \%$ of the respondents who did not have a college education were aware of this fact. Clearly, more work needs to be done to spread the message about high blood pressure in some parts of the African American community to raise perceived risk and susceptibility awareness.

Another prominent difference between the educationlevel cohorts was in their reported agreement regarding self-efficacy in prevention of heart disease. Only $51 \%$ of those without a college education strongly disagreed that they could not prevent heart disease in contrast to $84 \%$ of the college educated (Table 3). A similar divergence was observed with the level of comfort respondents had of talking with a medical doctor. While nearly three-quarters of the college educated strongly agreed they felt comfortable talking with their physician, only slightly over half of the non-college educated felt this way. These differences in responses suggest that persons who were not college educated may feel they have less control over their environment and ability to change risk factors. 
Table 5 Percent of Respondents Reporting Correctly on Heart Disease Knowledge (HDK) Questions

\begin{tabular}{|c|c|c|c|c|c|}
\hline HDK Statements & $\begin{array}{l}\text { Total } \\
(\mathrm{N}=172)\end{array}$ & $\begin{array}{l}\text { Male } \\
(n=62)\end{array}$ & $\begin{array}{l}\text { Female } \\
(n=110)\end{array}$ & $\begin{array}{l}\text { College } \\
(n=116)\end{array}$ & $\begin{array}{l}\text { No College } \\
(n=56)\end{array}$ \\
\hline Some forms of heart disease may result in a stroke. (T) & 95.9 & 95.2 & 96.4 & 96.6 & 94.6 \\
\hline $\begin{array}{l}\text { Heart disease develops gradually over many years \& can easily go undetected. } \\
\text { (T) }\end{array}$ & 92.4 & 90.3 & 93.6 & 93.1 & 91.1 \\
\hline Women are less likely to get heart disease after menopause than before. (F) & 77.3 & 72.6 & 80.0 & 77.6 & 76.8 \\
\hline $\begin{array}{l}\text { In the first few hours after the onset of heart attack or stroke symptoms, } \\
\text { treatments exist that can break up blood clots to reduce the damage. (T) }\end{array}$ & 75.4 & 72.1 & 77.3 & $84.5^{1}$ & $56.4^{1}$ \\
\hline $\begin{array}{l}\text { Black women are more likely than White women to die from a heart attack or } \\
\text { stroke. (T) }\end{array}$ & 73.8 & 77.4 & 71.8 & $81.0^{2}$ & $58.9^{2}$ \\
\hline $\begin{array}{l}\text { Hispanic women are more likely than White women to die from a heart attack } \\
\text { or stroke. (T) }\end{array}$ & 65.1 & 66.1 & 64.5 & $72.4^{3}$ & $50.0^{3}$ \\
\hline $\begin{array}{l}\text { The loss of estrogen is a significant contributor to the development of heart } \\
\text { disease in women following menopause. (T) }\end{array}$ & 59.3 & 56.5 & 60.9 & 61.2 & 55.4 \\
\hline $\begin{array}{l}\text { Women are more likely than men to have unusual or atypical symptoms of a } \\
\text { heart attack. (T) }\end{array}$ & 54.4 & 44.3 & 60.0 & 58.6 & 45.5 \\
\hline Men are more likely than postmenopausal women to have heart attacks. (F) & 52.9 & $40.3^{4}$ & $60.0^{4}$ & 52.6 & 53.6 \\
\hline Men and women experience the same symptoms of a heart attack. (F) & 46.5 & 41.9 & 49.1 & 48.3 & 42.9 \\
\hline $\begin{array}{l}\text { Once men are diagnosed with heart disease, they are more likely than women } \\
\text { to become seriously ill or die. (F) }\end{array}$ & 42.4 & $30.6^{5}$ & $49.1^{5}$ & 40.5 & 46.4 \\
\hline Heart disease is the leading cause of death in women. $(T)$ & 34.3 & $12.9^{1}$ & $46.4^{1}$ & 35.3 & 32.1 \\
\hline Summary index score & $7.7 \pm 1.9$ & $7.0 \pm 1.9^{1}$ & $8.1 \pm 1.7^{1}$ & $8.0 \pm 1.9^{6}$ & $7.0 \pm 1.7^{6}$ \\
\hline
\end{tabular}

Note. Data are \% correct. $T=$ True; $F=$ False. ${ }^{1} p=0.000 ;{ }^{2} p=0.002 ;{ }^{3} p=0.006 ;{ }^{4} p=0.017 ;{ }^{5} p=0.024 ;{ }^{6} p=0.001$.

Few participants (21\%) reported that their physicians had discussed heart disease or its prevention with them. Doctors may not see a need to discuss the issue of heart disease at such an early age if no signs of risk factors are present. While their younger age may indicate lower heart-disease risk, $44 \%$ of the group had one risk factor (smoking, engaging in insufficient exercise, or being overweight or obese). Almost $35 \%$ of the participants had two or more of these three possible risk factors. The low initiation of CVD discussion by doctors suggests that preventive education could be increased or that respondents were not seeing a doctor regularly. We

Table 6 Significant predictors of heart disease knowledge score, perceived susceptibility to heart disease and perceived self-efficacy

\begin{tabular}{lrrrr}
\hline Variable & $\begin{array}{r}\text { Beta (p } \\
\text { value) }\end{array}$ & $\begin{array}{r}\mathbf{F} \\
\text { value }\end{array}$ & $\begin{array}{r}\text { Adj } \\
\mathbf{R}^{2}\end{array}$ & $\begin{array}{r}\text { Model } \\
\mathbf{p}\end{array}$ \\
\hline Heart Disease Knowledge Score & & & & \\
Education Level & $.163(.027)$ & 11.66 & .158 & .000 \\
Sex & $-249(.001)$ & & & \\
Self-efficacy to prevent & $.223(.002)$ & & & \\
CVD & & & & \\
Perceived Self-Efficacy & & & & \\
Education Level & $.226(.003)$ & 6.81 & .064 & \\
Perceived low risk of CVD & $-.168(.025)$ & & & \\
Perceived Susceptibility to Heart Disease & & & \\
Sex & $.149(.049)$ & 4.08 & .035 & \\
Self-efficacy to prevent & $-.148(.051)$ & & & \\
CVD & & & & \\
\hline
\end{tabular}

did not ask about the sources of primary care or insurance status in our study. Some respondents may not have had insurance or a regular physician [35]. Recent analysis of National Health and Nutrition Examination Survey (NHANES) data shows that $59 \%$ of young adults (all races) have a CVD risk factor, but screening for cholesterol was less than 50\% among these at risk [36]. There may be a role for other contact agencies such as food assistance programs (e.g., WIC) to disseminate sources of CVD prevention information.

The prevalence of overweight or obesity (55\%) in our sample population was similar to that of the cohort of African Americans, aged 18-30 years old (57\%), in the Coronary Artery Risk Development in Young Adults (CARDIA) study conducted 1990-1991 [27]. Smoking was higher in the CARDIA group (36\%), than in the Phoenix sample (8\%). The differences in smoking prevalence may be driven by temporal changes in knowledge and behaviors more so than variations in awareness due to regional geography. Because the CARDIA study used open-ended questions whereas our research used a structured questionnaire, the different methodologies in the two studies preclude direct comparison of other CVD knowledge measures.

Overall, there were few differences in risk factors by gender in the sample population. Two notable exceptions were exercise and cholesterol screening. In contrast to their male peers, the young adult African American women in the study were unlikely to engage in physical activity or exercise. Barriers to physical 
activity for women are essential to identify because barriers are one of the key areas for risk reduction for heart disease, cancer, and diabetes. A positive finding was that $31 \%$ of the women had received cholesterol checks in the past 18 months. Since only $16 \%$ of men had a cholesterol check, targeted outreach for screening with men is warranted.

The HBM constructs fit well with some of our observations, but there are several inconsistencies within the participant responses. For example, knowledge of some CVD risk factors was quite high, but many participants who knew about these risk factors and had multiple risk factor characteristics did not perceive that they were at risk of CVD. Perceived severity and threat of CVD were relatively low. Self-efficacy for prevention was much higher among those with a college education but was not mediated by the number of risk factors. While the multivariate model for predicting knowledge was relatively strong, the other two models for predicting selfefficacy and perceived risk were not fully explained by the sociodemographic variables. As might be expected from previous studies, young adults did not recognize their own risk status [22,25-28,37].

To prevent heart disease in minority populations such as African Americans, who continue to experience disparities related to heart disease, assessing levels of knowledge about heart disease and initiating preventive measures in young adulthood will help prevention programs succeed. Although knowledge alone may be insufficient to change behavior, assessment of knowledge to develop culturally appropriate messages and determine salient leverage points to encourage behavior change as a first step increases program acceptance [27]. Baseline knowledge assessment as part of all health education and promotion projects during formative evaluation and piloting can make programs relevant, meaningful, and successful with the target audience.

There are several limitations to the study. The participants represent a cross-sectional convenience sample of self-identified, young, adult African Americans. Causality cannot be inferred from the observed associations because of this design. The sample was not random, and findings may not be representative of other young adult African Americans in other Arizona cities or elsewhere. Furthermore, because only African Americans were included in the study, it is not known if these results would be similar or different for same aged people of different ethnic backgrounds.

Despite these limitations, some of the variation observed in knowledge was unexpected. These findings substantiate that learning a health message does not always mean total understanding or the ability to think about it critically. An example is the relatively widespread knowledge that high cholesterol is a known cause of CVD but knowledge that animal products contain high cholesterol is not extensive.

\section{Conclusions}

Heart disease continues to be the leading cause of death for African Americans in Arizona and the rest of the nation, despite decreased death rates during the past several years. Possible tactics to prevent heart disease prevention tactics include increased awareness of risk factors and warning signs. Furthermore, heart disease knowledge could be increased, especially in regard to knowledge of specific risk factors and warning signs of heart attacks in women. The need for increased gender specific knowledge was evident in both male and female participants. By uncovering the reasons that prevent this minority age group from attaining an adequate level of knowledge about heart disease and from changing behaviors when the level of knowledge and health risk are both high, researchers may be able to make a significant contribution to reducing the prevalence of heart disease among young adults.

\section{Acknowledgements}

Funding for this project was provided in part by grant NTS0017 from St. Luke's Health Initiatives, Phoenix, Arizona, http://www.slhi.org. Its contents are solely the responsibility of the authors and do not necessarily represent the official views of St. Luke's Health Initiatives.

We thank the study participants for sharing their information and time. The authors thank the Neighbors That Care community group in South Phoenix, and the South Phoenix WIC clinic staff for their assistance with recruitment of participants. Dr. Alyssa Robillard, African and African American Studies, Arizona State University is gratefully acknowledged for her assistance in data collection and recruitment.

\section{Author details}

'Nutrition Program, College of Nursing and Health Innovation, Arizona State University, Mesa, Arizona, USA. ${ }^{2}$ Arizona Nutrition Network, Arizona

Department of Health Services, Phoenix, Arizona, USA.

\section{Authors' contributions}

DMW and KMJ designed the study together. KMJ conducted the data collection in the field, coordinated the project, drafted the manuscript, and assisted with statistical analysis. DMW revised the manuscript and statistical analysis. Both authors read and approved the final manuscript.

\section{Competing interests}

The authors declare that they have no competing interests.

Received: 24 August 2010 Accepted: 19 April 2011

Published: 19 April 2011

\section{References}

1. Rosamond W, Flegal K, Friday G, Furie K, Go A, et al: Heart disease and stroke statistics-2007 update: a report from the American Heart Association Statistics Committee and Stroke Statistics Subcommittee. Circulation 2007, 115:69e-171e.

2. Fincher C, Williams J, MacLean V, Allison JJ, Kiefe Cl, Canto J: Racial disparities in coronary heart disease: a sociological view of the medical literature on physician bias. Ethn Dis 2004, 14:360-371.

3. Callow AD: Cardiovascular disease 2005-the global picture. Vascular Pharmacology 2006, 45:302-307.

4. Barnett $\mathrm{E}$, Halverson J: Disparities in premature coronary heart disease mortality by region and urbanicity among Black and White adults ages 35-64, 1985-1995. Public Health Reports 2000, 115:52-64. 
5. Ferdinand KC: African American Heart Failure Trial: role of endothelial dysfunction and heart failure in African Americans. Am J Cardio 2007, 99: S3-S6.

6. Liburd LC, Jack L Jr, Williams S, Tucker P: Intervening on the social determinants of cardiovascular disease and diabetes. Am J Prev Med 2005, 29:18-24.

7. Crook ED, Clark BL, Bradford ST, Golden K, Calvin R, Taylor HA, Flack JM: From 1960s Evans County Georgia to present-day Jackson, Mississippi: An exploration of cardiovascular disease in African Americans. Am J Med Sciences 2003, 325:307-314.

8. Homko CJ, Santamore WP, Zamora L, Shirk G, Gaughan J, Cross R, Kashem A, Petersen S, Bove AA: Cardiovascular disease knowledge and risk perception among underserved individuals at risk of cardiovascular disease. J Cardiovasc Nurs 2008, 23:332-337.

9. Strecher VJ, Rosenstock IM: The Health Belief Model. In Health Behavior and Health Education.. 2 edition. Edited by: Glanz K, Lewis FM, Rimer BK San Francisco:Jossey-Bass; 1997:41-59.

10. Jones DE, Weaver MT, Grimley D, Appel SJ, Ard J: Health Belief Mode perceptions, knowledge of heart disease, and its risk factors in educated African-American women: An exploration of the relationships of socioeconomic status and age. J Natl Black Nurse Assoc 2006, 17:13-23.

11. Molaison EF: Stages of change in clinical nutrition practice. Nutr Clin Care 2002, 5:251-257.

12. Strolla LO, Gans KM, Risica PM: Using qualitative and quantitative formative research to develop tailored nutrition intervention materials for a diverse low-income audience. Health Education Research 2006, 21:465-476.

13. Campbell MK, Quintiliani L: Tailored interventions in Public Health: Where does tailoring fit in interventions to reduce health disparities? Am Behav Sci 2006, 49:775-793.

14. Mosca L, Ferris A, Fabunmi R, Robertson RM: Tracking women's awareness of heart disease: An American Heart Association national study. Circulation 2004, 109:573-579.

15. Pace R, Dawkins N, Wang B, Person S, Shikany JM: Rural African Americans' dietary knowledge, perceptions, and behavior in relation to cardiovascular disease. Ethn Dis 2008, 18:6-12.

16. Sellers RM, Smith MA, Shelton JN, Rowley SA, Chavous TM: Multidimensional model of racial identity: a reconceptualization of African American racial identity. Pers Soc Psychol Rev 1998, 2:18-39.

17. Lancaster KJ, Watts SO, Dixon LB: Dietary intake and risk of coronary heart disease differ among ethnic subgroups of Black Americans. J Nutr 2006, 136:446-451.

18. Liao Y, Greenlund KJ, Croft JB, Keenan NL, Giles WH: Factors explaining excess stroke prevalence in the US Stroke Belt. Stroke 2009, 40:3336-3341.

19. Whitaker MC: The rise of Black Phoenix: African-American migration settlement and community development in Maricopa County, Arizona 1868-1930. The Journal of Negro History 2000, 85:197-209.

20. Green LW, Kreuter MW, eds: Health Promotion Planning: An Educational and Ecological Approach. 3 edition. Mountain View, CA: Mayfield Publishing Company; 1999

21. Collins KM, Dantico M, Shearer NBC, Mossman KL: Heart disease awareness among college students. J Comm Hlth 2004, 29:405-420.

22. Vale A: Heart disease and young adults: Is prevention important? J Comm Hith Nurs 2000, 17:225-233.

23. Knowler WC, Barrett-Connor E, Fowler SE, Hamman RF, Lachin JM, Walker EA, Nathan DM: Diabetes Prevention Program Research Group. Reduction in the incidence of type 2 diabetes with lifestyle intervention or metformin. N Engl J Med 2002, 346:393-403.

24. Devine C: A life course perspective: Understanding food choices in time, social location, and history. JNEB 2005, 37:121-128.

25. Von Ah D, Ebert S, Ngamvitroj A, Park N, Kang D: Predictors of health behaviours in college students. J Adv Nurs 2004, 48:463-474

26. Frontini MG, Srinivasan SR, Elkasabany A, Berenson GS: Awareness of hypertension and dyslipidemia in a semirural population of young adults: the Bogalusa Heart Study. Prev Med 2003, 36:398-402.

27. Lynch EB, Liu K, Kiefe Cl, Greenland P: Cardiovascular disease risk factor knowledge in young adults and 10-year change in risk factors. Am J Epi 2006, 164:1171-1179.

28. Haire-Joshu D, Kreuter MK, Holt C, Steger-May K: Estimates of fruit and vegetable intake in childhood and adult dietary behaviors of African American women. JNEB 2004, 36:309-314
29. Arizona Department of Health Services: Arizona vital statistics: Differences in the health status among race/ethnic groups - 2007.[http://www.azdhs. gov/plan/report/dhsag/index.htm], Retrieved October 6, 2008,.

30. Centers for Disease Control and Prevention, Heart Disease \& Stroke Maps, Arizona - Heart Disease:[http://apps.nccd.cdc.gov/giscvh2/Results.aspx], Retrieved October 10, 2009

31. Owens CS: Diabetes and obesity risks in African American young adult freshmen attending a historically Black college/university. J Hlthcare Poor Underserv 2008, 19:1096-1118.

32. Christian AH, Rosamond W, White AR, Mosca L: Nine-year trends and racial and ethnic disparities in women's awareness of heart disease and stroke: An American Heart Association National Study. Journal of Women's Health 2007, 16:68-81.

33. Lutfiyya MN, Cumba MT, McCullough JE, Barlow EL, Lipsky MS: Disparities in adult African American women's knowledge of heart attack and stroke symptomatology: An analysis of 2003-2005 Behavioral Risk Factor Surveillance Survey data. J Women's HIth 2008, 17:805-813.

34. Pratt CA, Ha L, Levine SR, Pratt CB: Stroke knowledge and barriers to stroke prevention among African Americans: Implications for health communication. J Hith Comm 2003, 8:369-381.

35. Wagner J, Lacey K, Abbott G, de Groot M, Chyun D: Knowledge of heart disease risk in a multicultural community sample of people with diabetes. Annals of Behavioral Medicine 2006, 31:224-230.

36. Kuklina EV, Yoon PW, Keenan NL: Prevalence of coronary heart disease risk factors and screening for high cholesterol levels among young adults, United States, 1999-2006. Ann Fam Med 2010, 8:327-333.

37. Green JS, Grant M, Hill KL, Brizzolara J, Belmont B: Heart disease risk perception in college men and women. J Am Coll Hlth 2003, 51:207-211.

\section{Pre-publication history}

The pre-publication history for this paper can be accessed here: http://www.biomedcentral.com/1471-2458/11/248/prepub

\section{doi:10.1186/1471-2458-11-248}

Cite this article as: Winham and Jones: Knowledge of young African American adults about heart disease: a cross-sectional survey. BMC Public Health 2011 11:248

\section{Submit your next manuscript to BioMed Central and take full advantage of:}

- Convenient online submission

- Thorough peer review

- No space constraints or color figure charges

- Immediate publication on acceptance

- Inclusion in PubMed, CAS, Scopus and Google Scholar

- Research which is freely available for redistribution

Submit your manuscript at www.biomedcentral.com/submit
C Biomed Central 